\title{
Techno-economic Analysis of High-Temperature Thermal Energy Storage for On-Demand Heat and Power
}

Peng Peng ${ }^{1}$, Lin Yang ${ }^{2}$, Akanksha K. Menon ${ }^{2,3}$, Nathaniel Weger ${ }^{2,4}$, Ravi Prasher ${ }^{2,4}$, Hanna Breunig ${ }^{1, *}$, and Sean Lubner ${ }^{2}$

1. Energy Analysis and Environmental Impacts Division, Lawrence Berkeley National Laboratory, Berkeley, CA 94720, USA

2. Energy Storage \& Distributed Resources Division, Lawrence Berkeley National Laboratory, Berkeley, CA 94720, USA

3. George W. Woodruff School of Mechanical Engineering, Georgia Institute of Technology, Atlanta, GA 30332, USA

4. Department of Mechanical Engineering, University of California Berkeley, Berkeley, CA 94720, USA

*Correspondence: hannabreunig@lbl.gov

\begin{abstract}
Herein we present a concept of a high-temperature, thermal energy storage (HT-TES) system for largescale long duration energy storage ( $>10$ hours) applications. The system relies on tunable composite ceramic materials with high electrical conductivity and can output the stored energy flexibly in the form of heat at $1100{ }^{\circ} \mathrm{C}$ or higher, and as electricity. We model the performance and cost of the system in a techno-economic analysis to identify key material and system properties influencing viability. For applications with daily operation (12 hours storage duration), we find achieving levelized storage costs below US Department of Energy's $5 \mathbb{C} / \mathrm{kWh}_{\mathrm{e}}\left(1-2.5 \mathbb{C} / \mathrm{kWh}_{\text {th }}\right.$ equivalent) target by 2030 is possible. Candidate materials should have above 600-900 high-temperature cycle stability while offering at least $10^{4} \mathrm{~S} / \mathrm{m}$ of electrical conductivity. Our results suggest this system can be economical for longer storage durations (weeks to months) when coupled with intermittent charging using surplus renewable energy sources.
\end{abstract}




\section{INTRODUCTION}

New technologies are necessary to economically replace high-grade heat and uninterrupted power traditionally produced by fossil fuels with variable renewable energy (VREs) sources such as wind and solar. In particular, coupling continuous processes that require heat and power with intermittent electricity generation requires efficient, flexible and economical long-duration $(>10 \mathrm{hr})$ energy storage systems. ${ }^{1,2}$ Incumbent storage systems such as batteries, pumped storage hydropower, and hydrogen can be charged with VREs, but are not necessarily efficient or economical when used for long-duration energy storage. ${ }^{3,4}$ Additionally, these technologies require extra steps to convert the stored energy into heat, resulting in round-trip efficiencies (RTE) below 50\%. RTE represents the efficiency between charging the storage system and releasing the energy to the end-user.

One potential approach for the long duration storage of VREs is to use high temperature thermal energy storage (HT-TES; $1,000{ }^{\circ} \mathrm{C}$ to $2,500{ }^{\circ} \mathrm{C}$ ). HT-TES convert and store electrical energy in a material as heat via joule heating at close to $100 \%$ efficiency. ${ }^{5}$ This energy can later be supplied directly as high-grade heat using a heat transfer fluid (HTF), or it can be converted back to electricity using an appropriate heat engine (Figure 1 A). HT-TES offers five significant benefits for long duration energy storage: (1) unlike batteries the additional capital cost to increase storage capacity is very cheap, (2) the surface area-tovolume ratio decreases with increasing capacity, providing natural self-insulation and further reducing cost while improving RTE, (3) the technology is not constrained by particular geographic requirements, (4) the system can be charged with electricity and discharged as heat/electricity at the same time if necessary, (5) High-temperature industrial applications are difficult to meet using electricity, such as iron processing requires temperatures ranging from $\sim 900{ }^{\circ} \mathrm{C}$ to $1200{ }^{\circ} \mathrm{C},{ }^{6}$ and (6) heat is the safest form to store energy. ${ }^{7,8}$

While promising, recently proposed concepts for HT-TES have so far relied on known materials for storage that we believe have show-stopping limitations. Intuitively, candidate materials must be cheap and have sufficiently high thermal and electrical conductivity while still being stable at high temperatures. Liquid metal can be used as both the storage material and HTF, however special pumps are required to circulate metal under high temperature, and the system will have to operate above the melting temperature of the metal everywhere that it is pumped. ${ }^{9}$ This will limit the viability of this system to supply heat for lower temperatures for most industries (i.e., $130-700^{\circ} \mathrm{C}$ ) ${ }^{6}$

Other storage materials recently proposed include graphite, ceramics, and molten salts are used to store energy, and air or water serve as heat transfer fluids (HTFs). ${ }^{10,11}$ These materials also come with potentially show-stopping limitations. Graphite has a high melting point and electrical conductivity, but has drawbacks including reactivity with HTFs (i.e., air and $\mathrm{CO}_{2}$ ) and weak mechanical properties. ${ }^{12,13}$ Ceramics have desirable attributes of high temperature stability and have been conventionally used for high-temperature applications such as in refractory furnaces and crucibles. ${ }^{14}$ However, most economical ceramics are either electrically insulating (i.e., $\mathrm{Al}_{2} \mathrm{O}_{3}, \mathrm{MgO}$ ) or semiconducting (i.e., $\left.\mathrm{TiO}_{2}\right)^{15}$, 16 , which limits their ability to be charged rapidly using joule heating to convert electricity to heat for storage. Although these non-electrically conducting TES material can be heat via external heaters and HTFs, the number of energy conversion stages can be greatly lowered if these materials can be directly joule heated, thus reducing heat loss and system complexity. Silicon carbide is an electrically conductive ceramic, but has shape and size limitations at large-scale deployment. ${ }^{17}$

Therefore, the best material candidates for HT-TES could be ones (i.e., composite materials) that are engineered specifically for the application rather than picked from a list of what we already have. Motivated by this finding, our objective for this study was to better understand the relationship between 
material properties and target system-level cost and performance to guide subsequent material screening and synthesis work. We present a comprehensive process model and techno-economic analysis (TEA) to bound system performance and cost, and highlight the possibility of novel engineered composite materials.

To perform this work, we designed and modeled a HT-TES system that can store VRE and grid electricity to provide on-demand heat and electricity. We conducted rigorous mathematical modeling of all HT-TES components and subsystems (i.e., compression for the HTF, pipe, material manufacturing) under a range of operating conditions to evaluate the economic potential of this emerging technology. We present results for a large continuous high-temperature industrial application such as iron processing, that require working temperature as high as $1100{ }^{\circ} \mathrm{C} .{ }^{6}$

From our models, we obtain a full picture of the relationship between various system design parameters (i.e., heat loss, and storage duration) and their influence on systems (i.e., cost performance, energy consumption), which has not been studied even for TES at lower temperatures. We apply our analysis to evaluate how graphite, commercial ceramics, and a theoretical composite material perform and compare results with previously proposed HT-TES systems. Developing this capability allowed us to identify material and system development targets, including electrical conductivity, efficiency, material durability, and storage temperature, that would allow HT-TES to meet the 2030 levelized storage cost target identified by the U.S. Department of Energy (DOE) for long-duration stationary applications (in terms of electricity and equivalent thermal energy outputs). ${ }^{18}$ The results of this study offer critical guidance on future deployment of HT-TES technologies for specific applications.

\section{SYSTEM OVERVIEW AND ANALYSIS SCOPE}

The HT-TES system described in this study could be used to supply heat and electricity for various residential and commercial applications. Shown in Figure 1 (A), the heat output section includes the HTTES system, gaseous HTF, and other sub-components (i.e., compressors, splitters, piping) to transport the HTF and control its temperature. The system will be charged via joule heating to reach the storage temperature. During discharge, HTF flows through the HT-TES system, and delivers the stored heat to the end-user. Upon releasing the heat, the cold HTF circulates back from the end-user to the HT-TES where it is heated up again. For the HTF, we select the common inert gas $\mathrm{N}_{2}$. If the storage temperature is above $1400{ }^{\circ} \mathrm{C}$ and the material includes carbon, Argon is used as $\mathrm{N}_{2}$ will start to react with carbon. ${ }^{19}$

In recent years, academic and industrial research and development efforts have made it possible to convert high-temperature thermal energy into electricity using thermophotovoltaics (TPVs). ${ }^{9,20}$ Thus for the electricity output section, our system design incorporates the state-of-the-art TPV modules embedded in the HT-TES system. During discharge, the TPV modules transform the stored thermal energy to electricity, which is supplied to the end-user and to compressors in the heat output section. As shown in the system boundary in Figure 1 (A), our study focuses on modeling the HT-TES system for both heat and electricity outputs, as well as the coupled HTF, piping, compressor, mixer and splitters specific to the heat output section. Overall, the process model is based on mass and energy balances centered around the $\mathrm{HTF}$ at different stages of operation.

Shown in Figure 1 (B), the HT-TES system is a cuboidal structure comprised of HT-TES materials (with added internal surface area for heat exchange), insulation, and structural support. Recent literature has shown enhanced electric conductivity when graphite is added to ceramic materials (i.e., $\mathrm{ZnO}$ and $\mathrm{TiO}_{2}$ ). ${ }^{21}$ Thus, the composite material used in this system is ceramic sintered with graphite to provide high electrical conductivity while maintaining high mechanical strength. Material purchase and manufacturing 
cost for the HT-TES system, as well as the coupled subsystem costs (i.e., pipes and compressors) are determined from the process model described in detail in the Experimental Procedure section, and Supplementary Sections S2 and S3.

The TPV module subsystem is modeled using literature results for cost and efficiencies. This subsystem model is integrated into our process model as the TPV is responsible for supplying electricity to the enduser and compressors, and requires the HT-TES system to supply the necessary heat needed.

For a scenario where the HT-TES is used daily, we use energy demand profiles representative of a direct iron reduction facility to model a high-temperature end-user. The output consists of $79 \%$ heat, $21 \%$ electricity, and the application temperature ranges from $180{ }^{\circ} \mathrm{C}$ (analogous to boiler use) to $1100{ }^{\circ} \mathrm{C}$ (analogous to iron ore reduction). ${ }^{6}$ Key system parameters for this scenario are listed in Table 1. Other system and cost parameters, along with the detailed reasons for selection are described in Supplementary Sections S1 to S3. Economic parameters and conditions used in the TEA are included in Supplementary Tables S2 and S3.

In our main analysis, we assume operation involves a consistent daily charge and discharge pattern. Recent electricity market analysis suggests anywhere from 10 to 15 hours of low VRE availability and/or high electricity cost is typical. ${ }^{22}$ As such, we model a system that can discharge for 12 hours and assume the system is charged when there are abundant VREs, or when the electricity is cheap, and is discharged when electricity cost is high or VREs availability is low.

Given the rising number of power outage incidents in recent years ${ }^{23,24}$, reliable and resilient backup power solutions have also become increasingly important in energy infrastructure. Thus, in the Outlook section, we identify backup power as another potential use of this system, and compare it with the daily use case. Based on recent statistics of power outages in the U.S., ${ }^{25,26}$ we set the number of annual operation cycles to 15 to account for monthly maintenance and three potential outage conditions, and the target storage duration to be 96 hours according to the Standard for Emergency and Standby Power Systems. ${ }^{27}$

Table 1. Performance parameters for a HT-TES system providing daily heat and electricity (base case), and backup power (in the Outlook Section) to a direct iron reduction facility.

\begin{tabular}{|c|c|c|c|}
\hline Parameter & Unit & Daily use case & Backup case \\
\hline Power requirement & MW & $800^{28-30}$ & $800^{28-30}$ \\
\hline End-use temperature (higher bound) & ${ }^{\circ} \mathrm{C}$ & $1100^{6}$ & $1100^{6}$ \\
\hline $\begin{array}{c}\text { End-use temperature } \\
\text { (lower bound) }\end{array}$ & ${ }^{\circ} \mathrm{C}$ & $180^{6}$ & $180^{6}$ \\
\hline $\begin{array}{c}\text { Distance from TES system to end- } \\
\text { user }\end{array}$ & $\mathrm{m}$ & 20 & 20 \\
\hline $\begin{array}{c}\text { Annual operation cycles } \\
\text { Heat transfer fluid }\end{array}$ & N/A & 360 & 15 \\
\hline Discharge time & Hours & $12^{22}$ & $\mathrm{~N}_{2}$ \\
\hline
\end{tabular}



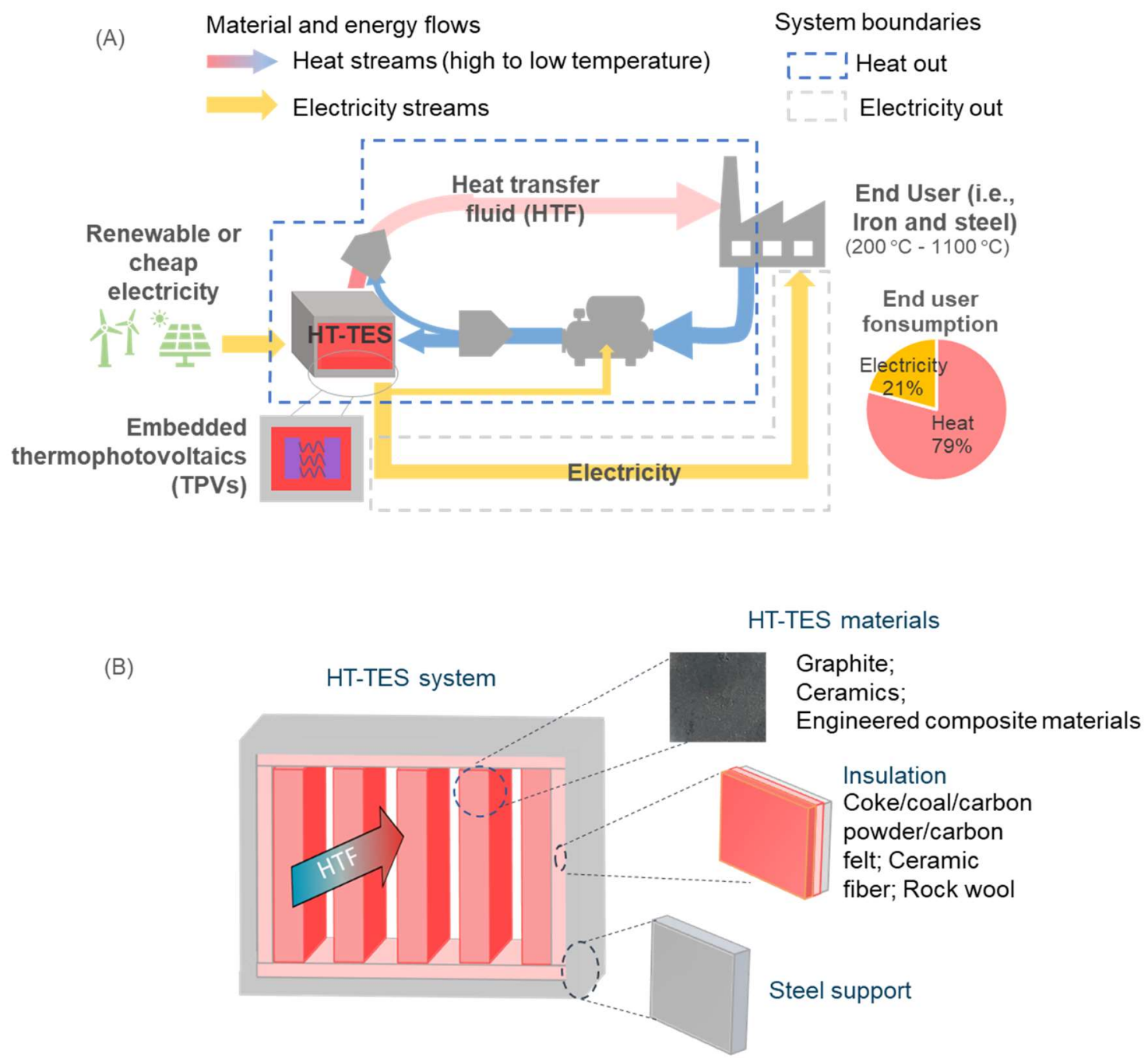

Figure 1. Overview of the HT-TES system

(A) Overview of how the HT-TES supplies heat and electricity to the end-user, system boundary, and scope of this study. Pie chart indicates the overall end-user energy consumption for iron and steel industry. ${ }^{6}$

(B) Overall design of the main HT-TES system

\section{RESULTS}

\section{Screening of Candidate Materials}

To screen the candidate materials for the HT-TES composite, we first analyze the hypothetical cost performance of individual materials, including graphite and ceramics, and compare their economic potential with previously reported TES systems.

Figure 2 (A) shows the estimated total system cost, which is the capital cost per $\mathrm{kWh}$ of output thermal energy $\left(\$ / \mathrm{kWh}_{\mathrm{th}}\right)$ for each of the candidate materials used in the HT-TES system in this study. The cost values are determined by running the process simulation and economic model described in 
Supplementary Section S2 and S3 for each of the candidate materials. A simulated manufacturing cost is estimated for each material based on its melting temperature, assuming it is sintered during the manufacturing process. The results show that all of these individual candidate materials could potentially offer at least the same range or lower costs $\left(7-40 \$ / \mathrm{kWh}_{\text {th }}\right.$ above $\left.1500^{\circ} \mathrm{C}\right)$ than the previously-studied latent and sensible HT-TES systems $\left(17-1000 \$ / \mathrm{kWh}_{\text {th }}\right.$ between 500 to $\left.1400{ }^{\circ} \mathrm{C}\right),{ }^{10,31,32}$ but with much higher storage temperatures (Figure 2(A)). As discussed in the Introduction Section and summarized in Table 2, most ceramics, or graphite alone cannot provide the necessary electrical conductivity and mechanical strength required for the HT-TES system. ${ }^{33-35}$

From our review, we find that an ideal candidate material for HT-TES should have low system cost, optimal and tunable electrical conductivity (this corresponds to the higher end of the conductivity range for the materials studied here, denoted by lighter colored circles), and high energy density (small size circles). The ideal candidate material should also have a high enough melting point $\left(200{ }^{\circ} \mathrm{C}\right.$ above the target application temperature). However, the melting temperature of the ceramic material should not be too high as this adds complexity to the sintering process (See Supplementary Section S3.2.1). Based on the selection criteria above, we identified aluminum oxide $\left(\mathrm{Al}_{2} \mathrm{O}_{3}\right)$ as a promising candidate material to be mixed with graphite, and model its theoretical performance. Other candidate ceramic materials, such as $\mathrm{TiO}_{2}$ and $\mathrm{MgO}$, can also be promising if they can be sintered easily with graphite.

Again, one of the potential advantages of using composite materials is being able to tune the electrical conductivity. Figure 2 (B) shows the required electrical conductivity, under the assumed constant representative supply voltages from the grid, ${ }^{36,37}$ to achieve target charging times of 0.1 to 24 hours. SiC, which is a relatively conductive ceramic material requires high voltage to enable charging times less than 12 hours. On the other hand, based on our prediction in Supplementary Section S3.2.1, graphite (30 $\mathrm{wt} \%)-\mathrm{Al}_{2} \mathrm{O}_{3}(70 \mathrm{wt} \%)$ composite material can offer desirable electrical conductivity $\left(10^{4} \mathrm{~S} / \mathrm{m}\right)$ to enable full charging below 12 hours across all voltage ranges, while keeping $\mathrm{Al}_{2} \mathrm{O}_{3}$ as the main component to maintain high mechanical strength to reliably hold shape during operation.

Table 2. Overview of the key advantages and disadvantages of candidate HT-TES materials.

\begin{tabular}{|c|c|c|c|}
\hline \multicolumn{2}{|c|}{ Materials } & Advantage & Disadvantage \\
\hline \multirow[b]{2}{*}{ Ceramics } & $\begin{array}{c}\mathrm{MgO} \\
\mathrm{Al}_{2} \mathrm{O}_{3} \text {, etc. }\end{array}$ & $\begin{array}{l}\text { - Strong mechanical properties } \\
\text { - Less reactive with common HTFs }\end{array}$ & - Low electrical conductivity \\
\hline & $\mathrm{SiC}$ & $\begin{array}{l}\text { - Strong mechanical properties } \\
\text { - High electrical conductivity }\end{array}$ & $\begin{array}{l}\text { - Size and shape limitation at } \\
\text { large scale } \\
\text { - Require inert HTF (i.e. Ar) } \\
\text { under high temperature }\end{array}$ \\
\hline \multicolumn{2}{|c|}{ Graphite } & - High electrical conductivity & $\begin{array}{c}\text { - Require inert HTF (i.e. Ar) } \\
\text { under high temperature } \\
\text { - Weak mechanical properties }\end{array}$ \\
\hline \multicolumn{2}{|c|}{$\begin{array}{c}\text { Engineered composite } \\
\text { material }\left(30 \mathrm{wt}^{2} \mathrm{C}+70\right. \\
\left.\mathrm{wt} \% \mathrm{Al}_{2} \mathrm{O}_{3}\right)\end{array}$} & $\begin{array}{l}\text { - Strong mechanical properties } \\
\text { - Tunable electrical conductivity } \\
\text { and density }\end{array}$ & $\begin{array}{l}\text { - Require inert HTF (i.e. Ar) } \\
\text { under high temperature }\end{array}$ \\
\hline
\end{tabular}




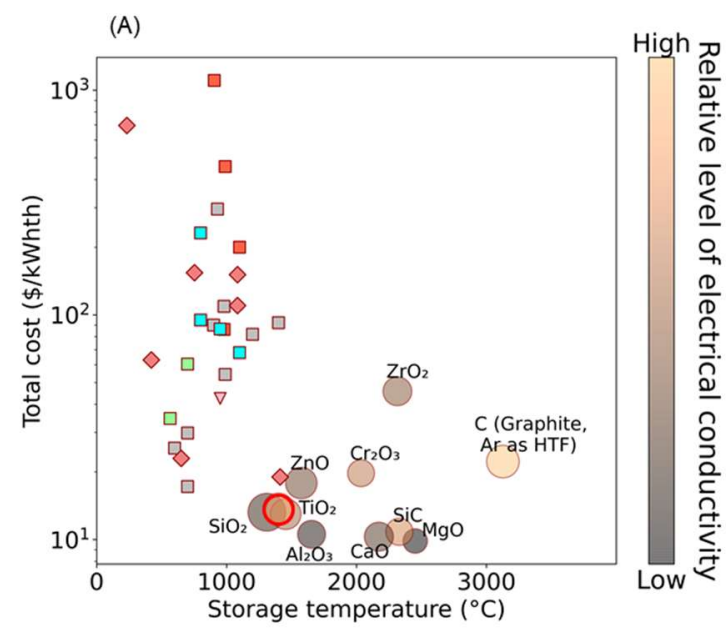

\author{
Literature values \\ - Molten salts \\ - Alkaline hydroxides \\ - Metal oxides (chemical) \\ - Chemical looping combustion \\ $\nabla$ Molten silicon \\ $\diamond \quad$ Miscibility gap alloys \\ This study (relative size) \\ Small

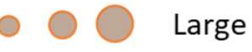 \\ Composite \\ (30 wt $\% \mathrm{C}+70$ wt $\% \mathrm{Al}_{2} \mathrm{O}_{3}$ )
}
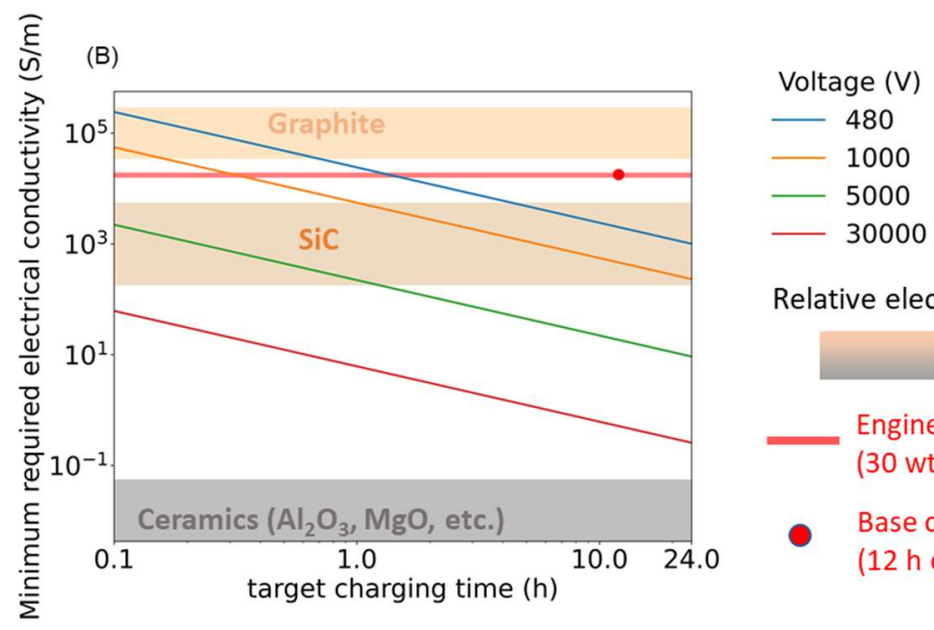

Figure 2. Electrical conductivity and overall cost performance of different existing and proposed HT-TES materials

(A) Potential economic performance for candidate composite materials for HT-TES in this study at maximum storage temperatures vs. performance range of previously-studied HT-TES systems. ${ }^{10,31,32}$ Value in this study includes all costs (i.e., compressors and piping) for the heat output section, including arbitrary material manufacturing (sintering) costs at $200{ }^{\circ} \mathrm{C}$ below the materials' melting point. Circle size represents the relative volume of the HT-TES system needed.

(B) Theoretical minimum required electrical conductivity for different target charging times and the approximate range of representative materials. The electrical conductivity of A12O3 and graphite composite is calculated using the Bruggeman model (See Supplementary Section S3.2.1), and the approximate ranges for ceramics and graphite are determined from literature. ${ }^{33-35}$ Analysis is done assuming the absolute value of the cross-sectional area equal the length of the TES structure. The values are qualitative assessment as it will change with the geometry. 


\section{Cost Breakdown and Sensitivity Analysis}

Figure 3 (A) shows the cost breakdown of upfront capital expenditure (\$) when using the base case composite $\left(\mathrm{Al}_{2} \mathrm{O}_{3}\right.$ and graphite) to supply heat and electricity to the iron reduction process. We find the system can output heat relatively efficiently and at lower cost than electricity. The cost of the electricity output section is almost the same as the heat output section, even though the electricity output accounts for only $21 \%$ of the total stored energy. This can be explained by the high cost of the TPV $(300 \$ / \mathrm{kW})$, and the low efficiency $(<50 \%)^{9,38,39}$ of converting heat to electricity compared with the minimal heat loss when using heat directly.

The largest HT-TES material-related cost is manufacturing, which is energy-intensive for materials with high melting temperature over $2000{ }^{\circ} \mathrm{C}$ (See Supplementary Section S3.2.1). Also, owing to the low cost of the composite materials $\left(0.3 \$ / \mathrm{kg}\right.$ for $\mathrm{Al}_{2} \mathrm{O}_{3}$ and $0.7 \$ / \mathrm{kg}$ for graphite), the upfront cost of the actual HT-TES system is comparable, and even cheaper than the cost of building the piping system to transport the gaseous HTF. As a result, TES material and HTF each contribute to $12 \%$, and $15 \%$ of the total capital cost for the base case, respectively.

Another critical indicator to assess is the levelized cost of storage (LCOS), which is the annualized discounted capital, operational, and material replacement costs, normalized by unit of energy discharged (see Experimental Procedure section for equation). For the base case shown in Figure 3 (B), the LCOS without charging are 3.4 cents per kilo-Watt thermal $\left(\mathbb{C} / \mathrm{kWh}_{\text {th }}\right)$ and 9.0 cents per kilo-Watt electricity $\left(\mathbb{C} / \mathrm{kWh}_{\mathrm{e}}\right)$.

These are compelling results given the DOE 2030 LCOS target for long-duration energy storage is set as $5 \mathbb{C} / \mathrm{kWh}_{\mathrm{e}}$ for electricity output. ${ }^{18}$ As there is limited guidance on LCOS target for thermal output directly used by industries, we estimate the equivalent thermal output target to be on the order of 1 to $2.5 \mathbb{C} / \mathrm{kWh}_{\text {th. }}$. We base this estimate on existing TPV efficiencies of 20-50\% to convert high-temperature thermal energy to electricity. ${ }^{9,38,39}$ Results in Figure 3 (B) suggest that with proper material development, both the heat and electricity output regions for this system have high potential to meet DOE's 2030 LCOS target, which we discuss in detail in the Material and System Development Targets Section.

Costs are sensitive to TES material cost, and Figure 3 (B) shows that after material replacement is included, the TES material cost starts to dominate within the LCOS. This finding led us to model and compare the cost performance of using $\mathrm{N}_{2}$ as $\mathrm{HTF}$ under $1400{ }^{\circ} \mathrm{C}$, and using Ar as HTF under slightly higher storage temperature of $1650^{\circ} \mathrm{C}$. Although Ar is more expensive than $\mathrm{N}_{2}$, it is potentially worth using higher storage temperatures, as less TES material is required under larger temperature difference (storage minus discharge). Furthermore, Figure 3 (C) shows that when the HTF is recycled at higher temperatures, meaning that the system is only used for high-temperature applications by the end-user, the system becomes less economical. Lowering the recycling temperature of HTF will not only ensure that the stored energy is fully delivered to the end-user, but also allows the HTF to be transported back at higher density, thus reducing the number of pipes needed. Therefore, it is critical for the end-user to discharge the delivered heat efficiently.

Aside from the HTF and necessary storage temperature, several other parameters can influence cost. Figures 3 (C) and (D) show the impact of varying key system-level parameters on the cost of the HT-TES system for the heat (Figure 3 (C)) and electricity output (Figure 3 (D)) sections. For the electricity output region in Figure 3 (D), the RTE is much lower because it is limited by the TPV efficiency when converting heat to electricity, which is generally below $50 \% .{ }^{9,38,39}$ Therefore, in order to help reach the DOE's $5 \mathbb{C} / \mathrm{kWh}$ LCOS target ${ }^{18}$ for the electricity output region, more efficient and economical TPV 
systems must be developed in addition to developing more economical and durable HT-TES materials. For both energy output forms, RTE, storage temperature, and material cycle life are the three most influential factors on the LCOS.
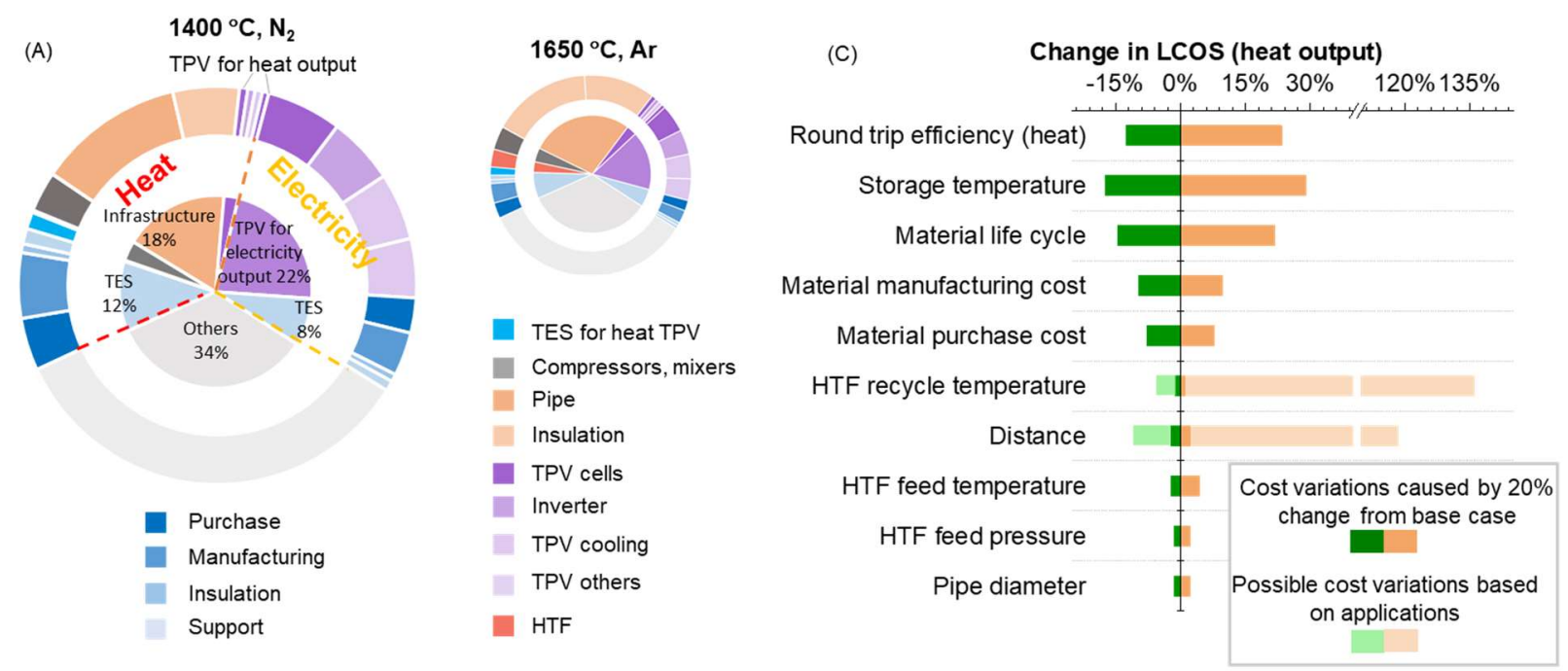

(D)
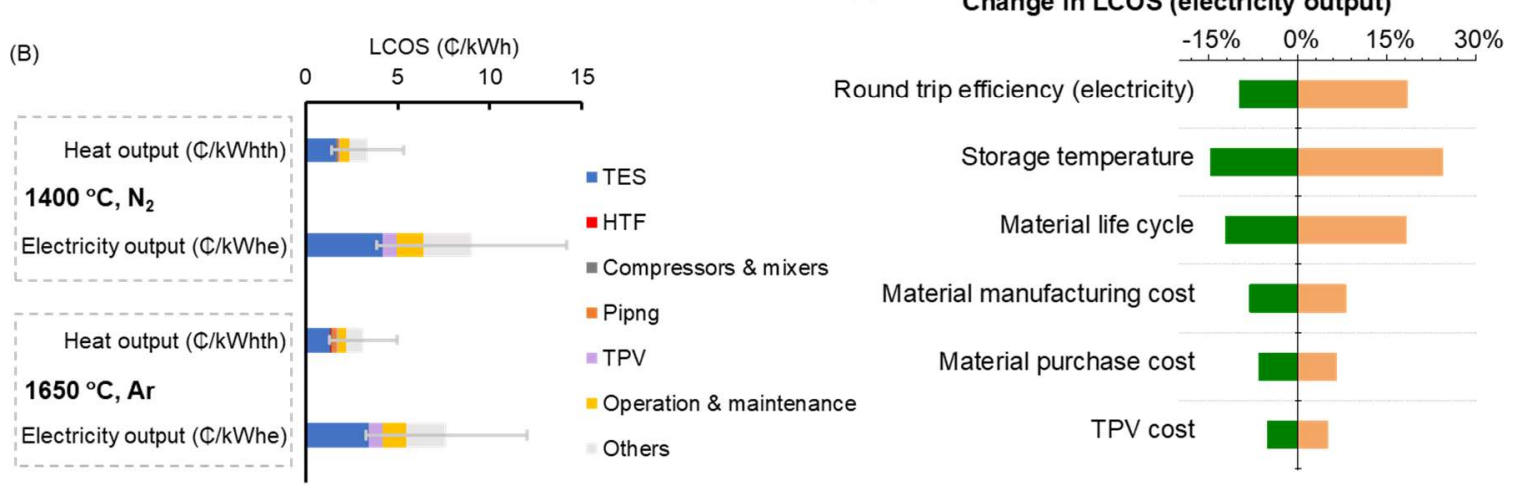

Figure 3. Cost breakdowns of the HT-TES system and sensitivity analysis for key system-level parameters.

(A) Breakdown of upfront capital expenditures for representative base case scenario using $\mathrm{Al}_{2} \mathrm{O}_{3}(70 \mathrm{wt} \%)$ and graphite (30 wt $\%$ ) to store energy for the iron and steel industry, which requires $79 \%$ of thermal energy and $21 \%$ electric energy. "Others" includes the plant construction, contingency, etc."TPV for heat output" means the TPV used to provide electricity to the equipment (mainly compressor) used for heat output.

(B) Cost breakdowns of levelized cost of storage for the HT-TES system.

(C) Sensitivity analysis for the heat output region. Bars show the relative cost influence between the parameters at $20 \%$ variance from the base-case values, which can be used to compare the relative impacts of these parameters.

(D) Sensitivity analysis for the electricity output region. Bars show the relative cost influence between the parameters at $20 \%$ variance from the base-case values, which can be used to compare the relative impacts of these parameters.

However, the overall LCOS could be highly affected if the heat is not efficiently used. In theory, heat transfer is more efficient than converting heat to electricity. Thus, in Figure 3 (C), the RTE for the heat 
output region is $86 \%$ based on the charging efficiency and utilization efficiency by the end-user (See details in Supplementary Section S2.1). Therefore, the base value is relatively close to the maximum value $(\sim 100 \%)$. Other system design parameters such as the distance, pressure, velocity, and returning temperature of HTF between the HT-TES system and the end-user are critical.

The high impact of distance shows that the HT-TES system is most suitable for on-site energy storage and generation, and should be ideally placed as close as possible to the end-user's heat supplying unit (i.e., furnace, reboiler, and kiln). It should be noted that for the heat output region (Figure 3 (C)), the pressure, and velocity can increase significantly with the distance to the end-user. Thus, when considering other applications/industries for future studies, the HT-TES should be placed close to the central heating device, such as steam boiler for district heating. If long-distance transportation of HTF is necessary, it is recommended to use, or integrate the HTF transportation with existing pipe infrastructures, such as natural gas for both on-site and long-distance transportation. In this case, the complex relationships between compressor, pipe, and the amount of HTF required should also be carefully considered. A discussion on this issue and example results using Ar as HTF can be found in Supplementary Section S4.1.

\section{DISCUSSION}

\section{Material and System Development Targets}

The primary purpose of using the graphite and ceramic composite material proposed in this study is to understand the system-level benefits of developing a storage material that can offer satisfactory electrical conductivity and high durability. Therefore, it is critical to set target for electrical conductivity and durability of the composite material, and derive the charging rate and maximum cycle life of the HT-TES system, respectively. These values represent important new information as optimal electrical conductivity allows the system to be charged faster under reasonable voltages and currents, and high cycle life means that less material replacement is required throughout the system's lifetime.

System simulation and TEA modelling (See Supplementary Sections S2 and S3) allowed us to understand how different graphite weight fractions affect the density, and therefore heat capacity of the composite material, which further change the cost performance. Figure 4 (A) shows that under the base material purchase cost used in this study, $0.7 \$ / \mathrm{kg}$ for graphite and $0.3 \$ / \mathrm{kg}$ for $\mathrm{Al}_{2} \mathrm{O}_{3}$ (Supplementary Section $\mathrm{S} 3.2 .1$ ), the system is more economical when slower charging times are allowed. However, as electrical conductivity gets below the percolation threshold, (around $10^{3} \mathrm{~S} / \mathrm{m}$ as shown in Supplementary Figure S6), a significant drop in electrical conductivity occurs with only minor decreases in the graphite weight fraction. As a result, too slow of charging time (i.e., above 24 hours) will not only make the electrical conductivity harder to control, but have little benefit in terms of lowering the LCOS.

Figures 4 (B) and (C) show the effects of material cycle life and storage temperature on the LCOS. There is limited stability data for conductive metal-oxide composites under joule heating HT-TES cycles, and the relationship between cycle life and storage temperature is poorly understood. A recent study reported a 6 to 10 year life span for industrial-use of non-conductive metal-oxide composites, such as bricks used in industrial kilns, at around 160 hours per cycle of high temperature operation. ${ }^{40}$ Assuming 360 days of operation, this value represents a cycle life of roughly 320 to 531 cycles. Lab-scale experiments reported 80 cycles for complex functional ceramic materials used in high-temperature $\left(1000-2000{ }^{\circ} \mathrm{C}\right)$ thermochemical applications. ${ }^{41}$ 
(A)

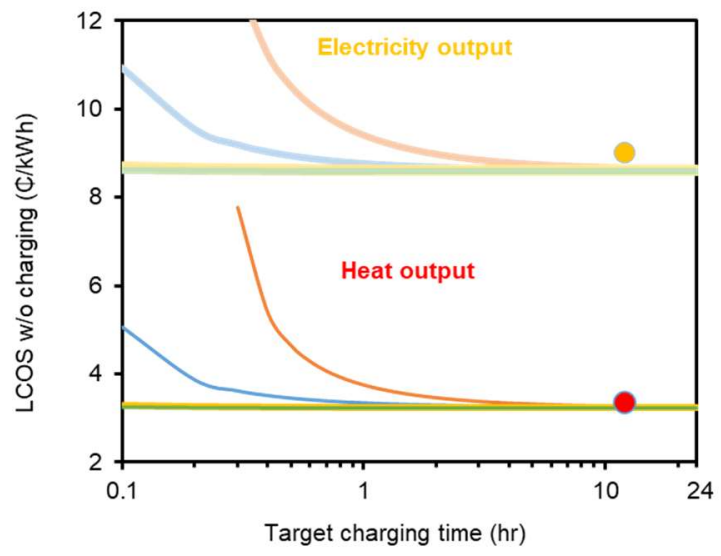

(C)

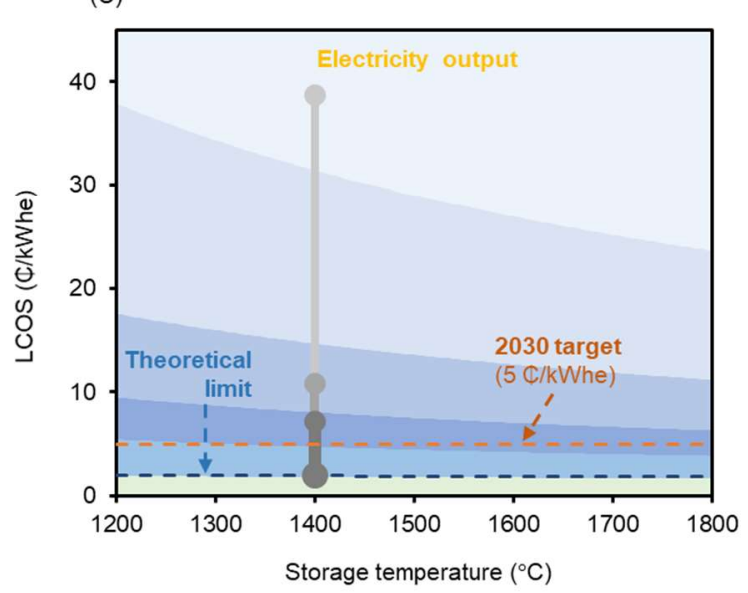

(B)

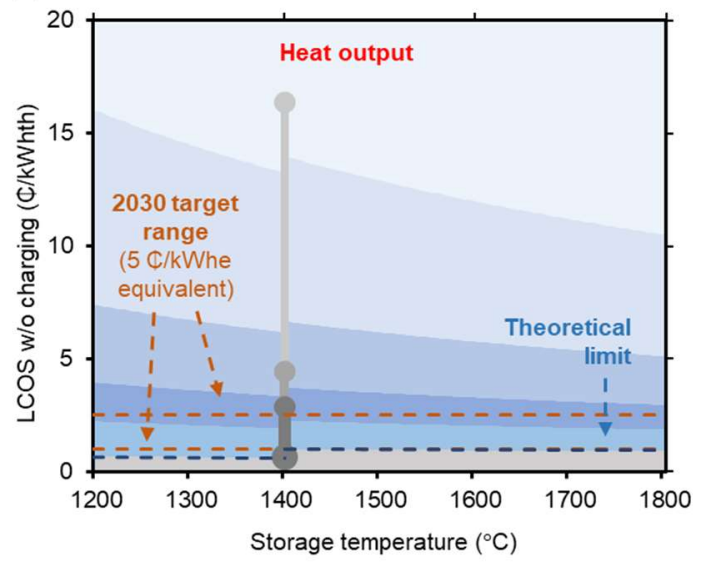

Legend

(A) Voltage (V)

$=480=1000$

B Base case, electricity output $\quad 5000-30000$

(B) and (C)

\# of cycles to failure

$<100$

$100-225$

225-450

450-900

$>900$

HTF $\left\{\begin{array}{l}>1400^{\circ} \mathrm{C}: \mathrm{Ar} \\ \leq 1400^{\circ} \mathrm{C}: \mathrm{N}_{2}\end{array}\right.$
Possible cycle life ranges based on relevant literature:

80 cycles

metal oxides (fast

320 cycles

Low-conducitivty metal xides for industrial kilns (slow cycle, multiple days)

530 cycles

7200 cycles Optimum range

Figure 4. Analysis of critical material development targets (electrical conductivity, cycle life, and storage temperature)

(A) Cost performance of the HT-TES system when aiming for different target charging times under the base case conditions (See Table 1), assuming 400 material cycle life. Line width is varied for aesthetic purpose only.

(B) Cost effects of storage temperature and material cycle life for the heat output region. "Theoretical limit" stands for LCOS when HT-TES material only needs to be replaced once during the system's lifetime.

(C) Cost effects of storage temperature and material cycle life for the electricity output region.

Using the above reported range of cycle life in our model leads to a LCOS range of 0.5 to $17.5 \mathbb{C} / \mathrm{kWh}$ th (Figure $4(\mathrm{~B})$ ) and 2.0 to $16.5 \mathrm{C} / \mathrm{kWh}_{\mathrm{e}}$ (Figure $4(\mathrm{C})$ ) at the base-case storage temperature of $1400{ }^{\circ} \mathrm{C}$ for this system. When material cycle life is low, the material purchase cost and manufacturing costs will play more significant role in the LCOS. Beyond the electrical conductivity and charging time, attaining the storage temperature at shorter charging times represents a higher temperature ramp rate. Rapid changes in operation can affect the material cycle life due to thermal shock issues within the storage material.

Considering uncertainties in costs and potential decrease of cycle life with storage temperature, Figure 4 (B) shows that for this HT-TES system to reach between 1 to $2.5 \mathbb{C} / \mathrm{kWh}_{\text {th }}$ LCOS for thermal applications, ${ }^{9}, 18,38,39$ the composite materials need to have a stable performance of at least approximately 600 cycles under $1800^{\circ} \mathrm{C}$ storage temperature, and above 800 cycles under $1200{ }^{\circ} \mathrm{C}$. 
Whereas for electricity output section (Figure $4(\mathrm{C})$ ), the composite HT-TES material should have a cycle life above 900 to reach the $5 \mathrm{C} / \mathrm{kWh}_{\mathrm{e}}$ target. ${ }^{18}$ As such, although improving the efficiency and lowering the cost of TPV is critical, a composite material that can offer over 1000 stable cycles can also help ensure the LCOS target with existing TPVs.

Besides electrical conductivity and durability, thermal conductivity is another critical material property that determines the discharge rate of the process. Previous studies have demonstrated that ceramics can discharge heat sufficiently for various TES applications. ${ }^{17}$ Since the thermal conductivity of graphite (25$470 \mathrm{~W} / \mathrm{m} \cdot \mathrm{K}$ ) is on the same level or higher than ceramics (i.e., $\mathrm{Al}_{2} \mathrm{O}_{3}$ at $6-33 \mathrm{~W} / \mathrm{m} \cdot \mathrm{K}$ ), ${ }^{42,}{ }^{43}$ it is reasonable to assume that our proposed composite mixture is able to meet the discharging heat transfer requirement for the proposed high-temperature applications. However, future studies are encouraged to analyze the required thermal conductivity, and to better understand how the temperature-dependent heat transfer under various geometries affects cost.

\section{Outlook}

Since the proposed HT-TES system can discharge the stored energy as both electricity and heat, it can be self-sustaining. Therefore, the HT-TES system could potentially be a good resource for providing backup power to the end-user when experiencing energy outages. The main difference between a backup application and an industrial or grid support application is the number of annual cycles. In this analysis, lower annual operation cycle is concurrent with longer hours of storage.

The main challenge with storing energy for longer hours under high temperature is to prevent heat loss. In the base case scenario, we assume $0.5 \%$ heat loss for 360 annual charge/discharge cycles. If the system is used less frequently, and for each cycle to store heat for longer hours, the cost penalty for insulation will increase. Specifically, the cost to maintain the same $0.5 \%$ heat loss will increase dramatically as storage hour reaches beyond 3 days, which is equivalent to around 100 annual charge/discharge cycles (blue lines in Figure 5 (A)). On the other hand, if the same heat loss rate is maintained, rather than the total percent heat loss for longer storage hours, the system will be much cheaper, as shown by the orange lines. For example, if the system needs to store heat for 27 days, it would be a lot cheaper to maintain the same heat loss rate as if it were to store heat for 12 hours. But in this case, the overall heat loss will be $30 \%$ of the energy stored.

When operating at increased annual cycles (shorter storage duration), less insulation is needed at the same target total heat loss percentage since less heat is stored at maximum temperature, but the system requires more replacement of HT-TES materials. This trade-off (light blue line in Figure 5 (A)) needs to be considered carefully when designing the operation pattern of this system. But when the number of annual cycles goes above 130 (equivalent to storing heat for around 2 days), the difference in system cost and LCOS between the two designs become negligible $(<5 \%)$, which means that it is economical to target small heat loss $(<1 \%)$ below the 2-day storage duration.

For ideal backup applications, the system should not only be able to store energy for longer duration, but also offer larger storage capacity. Figure 5 (B) and (C) shows the breakdown of the proposed backup HTTES system at 96 hour discharge capacity and 15 annual cycles for backup application (backup + maintenance runs). 

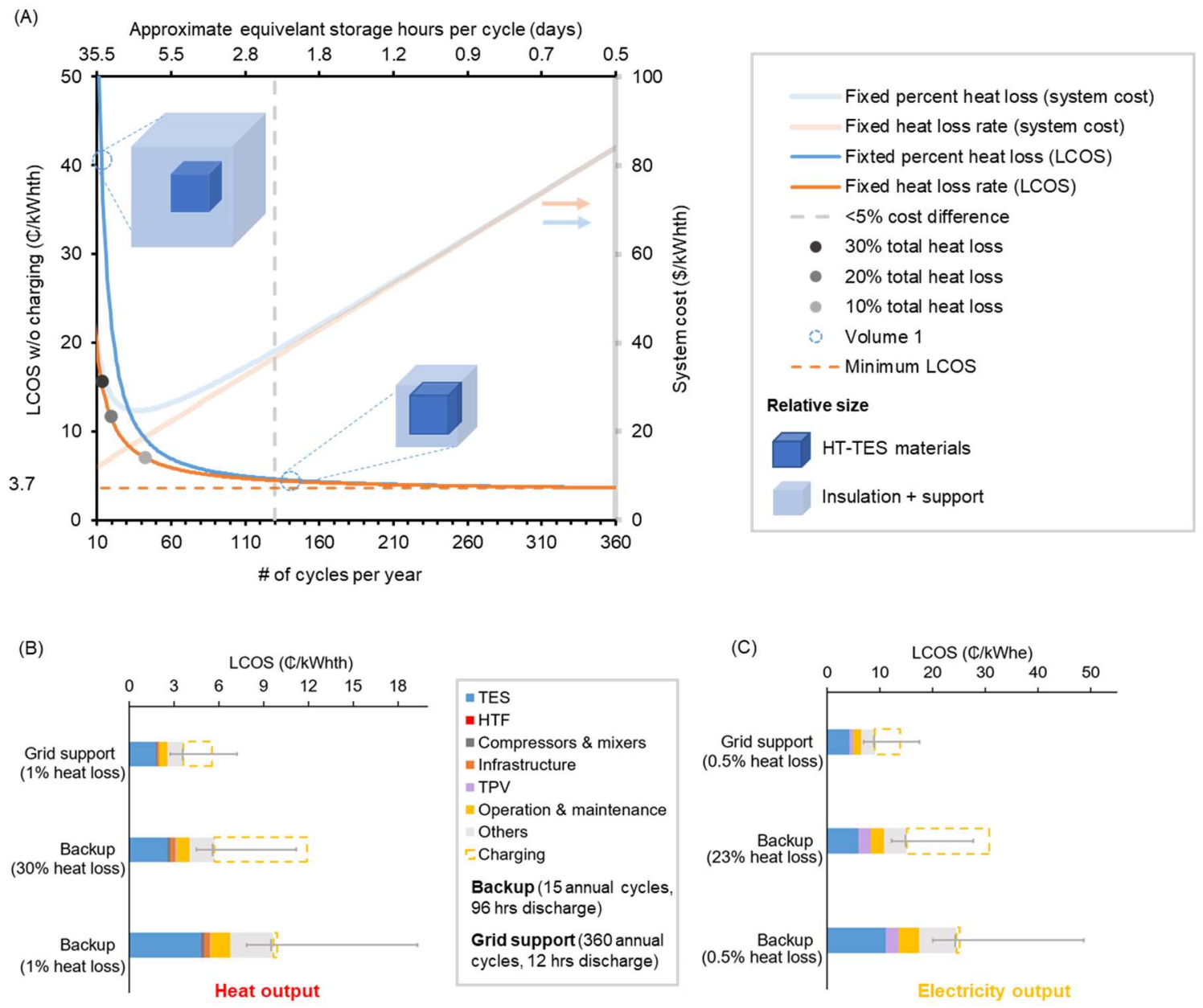

Figure 5. Cost performance of the HT-TES system for other potential applications.

(A) LCOS, system cost, and relative size of the HT-TES system with respect to the number of operating cycles per year for 12-hour discharge per cycle under two scenarios: fixed percent heat loss (blue) and fixed heat loss rate (orange). Results are for the heat output region. Both the insulation cost and its affects towards total LCOS decreases with storage duration, so "Minimum LCOS" is defined as the cost to maintain $0.5 \%$ heat loss for the shortest storage duration of 12 hours (equivalent to 360 annual charge/discharge cycles).

(B) and (C): Breakdown of LCOS for using the HT-TES system for backup applications vs. grid support for heat (B) and electricity $(\mathrm{C})$ output regions. The target heat loss is less for the electricity output region because it does not involve piping to transfer the HTF. Dashed lines account for the electricity cost of the charging process coupled with different storage scenarios. $\mathbb{C} / \mathrm{kWh}_{\mathrm{th}}$ and $\mathbb{C} / \mathrm{kWh}$ denote $\mathrm{LCOS}$ for direct thermal energy and electricity output, respectively.

The trend in Figure 5 (A) continues to hold for both heat and electricity output region when the storage duration is increased to 96 hours for the backup application. The LCOS of the HT-TES system itself is significantly cheaper when more heat loss is allowed (30\% vs. 1\%). Although more charging energy is required as the system becomes less efficient, the charging cost can be flexible for backup applications. For example, when coupled with renewable sources, backup application can allow the HT-TES system to be charged intermittently by the energy when the renewable source is abundant, which can greatly reduce 
the net charging cost. Furthermore, the heat loss during storage can also be used for daily operations, which requires careful optimization to integrate the HT-TES system to the end-user. Such renewable and end-use coupling is critical and should be one important direction for future research.

\section{CONCLUSIONS}

In this study, we developed a robust system design, process model, and TEA framework for HT-TES systems offering either electricity or heat over $1000{ }^{\circ} \mathrm{C}$. We evaluate the economic viability and set material and cost targets. We find that engineered composites using ceramic and graphite that achieve high electric conductivity and durability can potentially offer an economical solution for long duration energy storage (10 hours to 1 month).

The proposed HT-TES system can discharge energy flexibly via heat or electricity, and can be completely self-sustaining. Our cost analysis shows that the system outputs heat relatively cheaper than electricity. Both forms of energy outputs can potentially meet the $5 \mathbb{C} / \mathrm{kWh}_{\mathrm{e}}\left(1-2.5 \mathbb{C} / \mathrm{kWh}_{\mathrm{th}}\right.$ equivalent) levelized energy storage cost target with proper material development and system design.

For material development, one key target is to increase the durability and stability of ceramic composite materials under high-temperature cycling. Our analysis shows that to meet the $5 \mathbb{C} / \mathrm{kWh}_{\mathrm{e}}\left(1-2.5 \mathbb{C} / \mathrm{kWh}_{\text {th }}\right.$ equivalent) energy storage cost target, the ceramic should survive a maximum number of cycles over their life of above 600 and 900 for the heat and electricity output regions, respectively.

At the system level, fully utilizing stored heat, minimizing heat loss, and discharging the HTF at as low a return temperature as possible can reduce costs. We also identify and analyze the complex effects of delivering distance, HTF selection, and transportation velocity. These factors, critical yet rarely investigated in previous studies, can influence the infrastructure and balance of plant needed for this system, (i.e., pipes and compressors), and should be carefully designed based on specific end-use.

Our approach can be used to explore a wide range of applications of HT-TES. We demonstrate this capability by modeling an alternative application where the system is used for 96 hours of backup power. While allowing more heat loss during long duration storage can ultimately lower system costs, economics would improve the end-user can efficiently utilize the dissipated heat during long-duration storage. Future studies should optimize the upstream renewable coupling, charge/discharge, and heat utilization pattern based on representative local renewable availability and energy usage patterns.

\section{EXPERIMENTAL PROCEDURES}

The key components and system boundary of this analysis are shown in Figure 1 (A). For the process model and TEA, this study focuses on modeling the HT-TES system used for both the heat and electricity output region, as well as its coupled HTF, piping, compressor, mixer and splitters for the heat output region. As described previously, the model developed in this study takes minimum key inputs, such as the application temperature of the end-user and the storage temperature of the HT-TES system, to determine the rest of the temperature and pressure conditions, power requirements of different unit operation, and the amount of HT-TES materials and infrastructure needed, which includes pipe and the related insulation during HTF transport. The model is based on a mass and energy balance approach around the HTF at different process stages, which is described in detail in Supplementary Section S2.

System cost and LCOS are the two primary cost parameters studied for the HT-TES system. We use system cost to compare TES systems across storage capacities. System cost is defined as the fixed capital 
investment $\operatorname{cost}\left(\left(\sum c_{p}^{0}\right)\right.$ normalized by the storage capacity (Capacity in MWh) using Equation (1), which is applicable to both heat and electricity output cases.

System cost $\left(\$ / k W h_{\text {th/e }}\right)=\frac{\sum c_{p}^{0}}{P_{\text {target }} \cdot t_{\text {target }} \cdot \frac{1000 \mathrm{~kW}}{1 M W h}}$

where $\mathrm{P}_{\text {target }}$ and $\mathrm{t}_{\text {target }}$ are the target discharge power (MW) and time (hours), respectively. Another important cost factor evaluated in this study is the levelized cost of storage (LCOS), which is the annualized discounted cost per unit of discharged thermal or electricity energy within the system's operating lifetime ( $n$ years). ${ }^{44}$ To calculate LCOS, a capital recovery factor $(C R F)$ is calculated as shown in Equation (28) based on the real discount rate $(j)$.

$C R F=\frac{j(1+j)^{n}}{(1+j)^{n}-1}(2)$

The LCOS is then calculated from the $C R F$ and annual discharge capacity using Equation (29), where the tax rate (Tax), and the present value of depreciation $\left(D_{p v}\right)$ were determined from the latest NREL's Energy Analysis documentations. ${ }^{45}$ Values for these cost parameters are summarized in Table S2 in Supplementary Section S3.1. The LCOS is further calculated using Equation (3),

$\operatorname{LCOS}\left(\$ / k W h_{\text {th } / e}\right)=\frac{\left(\sum C_{p}^{0}\right) \cdot C R F \cdot\left(1-T_{a x} \cdot D_{p v}\right)}{P_{\text {target }} \cdot t_{\text {target }} \cdot \frac{1000 \mathrm{kWh}}{1 \mathrm{MWh}} \cdot n_{\text {cycles }} \cdot(1-\text { Tax })}+\frac{\sum \text { Annual O\&M Costs }}{P_{\text {target }} \cdot t_{\text {target }} \cdot n_{\text {cycles }}}$

where $\mathrm{n}_{\text {cycles }}$ is the number of annual operation cycles. The first and second term of Equation (3) account for capital cost, and operation and maintenance (O\&M) of the HT-TES system, respectively. More details of the cost analysis on how each capital and O\&M costs are calculated can be found in Supplementary Section S3.

\section{ACKNOWLEDGMENTS}

The authors gratefully acknowledge support from the U.S. Department of Energy under Contract No. DEAC02-05CH1 1231 with the Lawrence Berkeley National Laboratory. The authors would like to acknowledge the Laboratory Directed Research and Development (LDRD) Program at the Lawrence Berkeley National Laboratory for funding. The authors also thank Antora Inc. and Electrified Thermal Solutions for inputs on the system simulation and cost analysis. The United States Government retains and the publisher, by accepting the article for publication, acknowledges that the United States Government retains a nonexclusive, paid-up, irrevocable, worldwide license to publish or reproduce the published form of this manuscript, or allow others to do so, for United States Government purposes.

\section{AUTHOR CONTRIBUTIONS}

Conceptualization, H.B., S.L., and R.P.; Methodology, P.P., H.B., and S.L.; Investigation, H.B., and P.P.; Resources: L.Y., A.M., N.W.; Data Curation: P.P., Writing - Original Draft, P.P. and H.B.; Writing Review \& Editing, H.B., P.P., S.L., L.Y., A.M., N.W., and R.P.; Visualization: P.P. and H.B., Funding Acquisition, Resources, and Supervision, H.B., S.L., and R.P..

\section{DECLARATION OF INTERESTS}

The authors declare no competing interests. 


\section{REFERENCES}

1. Thiel, G. P.; Stark, A. K.(2021). To decarbonize industry, we must decarbonize heat. Joule, 5 (3), 531-550.

2. Albertus, P.; Manser, J. S.; Litzelman, S.(2020). Long-duration electricity storage applications, economics, and technologies. Joule, 4 (1), 21-32.

3. Mongird, K.; Viswanathan, V.; Alam, J.; Vartanian, C.; Sprenkle, V.; Baxter, R.(2020). 2020 Grid Energy Storage Technology Cost and Performance Assessment. U.S. Department of Energy, 2020.

4. $\quad$ Xu, L.; Lu, Y.; Zhao, C. Z.; Yuan, H.; Zhu, G. L.; Hou, L. P.; Zhang, Q.; Huang, J. Q.(2021). Toward the Scale-Up of Solid-State Lithium Metal Batteries: The Gaps between Lab-Level Cells and Practical Large-Format Batteries. Advanced Energy Materials, 11 (4), 2002360.

5. Hogervorst Cvejić, J.; Atanacković Krstonošić, M.; Bursać, M.; Miljić, U.(2017). Chapter 7 Polyphenols. In Nutraceutical and Functional Food Components, Galanakis, C. M., Ed. Academic Press: 2017; pp 203-258.

6. McMillan, C. A.; Ruth, M.(2019). Using facility-level emissions data to estimate the technical potential of alternative thermal sources to meet industrial heat demand. Applied Energy, 239, 1077-1090.

7. Henry, A.; Prasher, R.; Majumdar, A.(2020). Five thermal energy grand challenges for decarbonization. Nature Energy, 5 (9), 635-637.

8. Laughlin, R. B.(2017). Pumped thermal grid storage with heat exchange. Journal of Renewable and Sustainable Energy, 9 (4), 044103.

9. Amy, C.; Seyf, H. R.; Steiner, M. A.; Friedman, D. J.; Henry, A.(2019). Thermal energy grid storage using multi-junction photovoltaics. Energy \& Environmental Science, 12 (1), 334-343.

10. Meroueh, L.; Chen, G.(2020). Thermal energy storage radiatively coupled to a supercritical Rankine cycle for electric grid support. Renewable Energy, 145, 604-621.

11. Forsberg, C. W.; Stack, D. C.; Curtis, D.; Haratyk, G.; Sepulveda, N. A.(2017). Converting excess low-price electricity into high-temperature stored heat for industry and high-value electricity production. The Electricity Journal, 30 (6), 42-52.

12. Khare, S.; Dell'Amico, M.; Knight, C.; McGarry, S.(2013). Selection of materials for high temperature sensible energy storage. Solar Energy Materials and Solar Cells, 115, 114-122.

13. Turkdogan, E. T.; Koump, V.; Vinters, J. V.; Perzak, T. F.(1968). Rate of oxidation of graphite in carbon dioxide. Carbon, 6 (4), 467-484.

14. Fahrenholtz, W. G.; Wuchina, E. J.; Lee, W. E.; Zhou, Y.(2014). Ultra-high temperature ceramics: materials for extreme environment applications. John Wiley \& Sons: 2014.

15. Adler, D.(1970). Electrical and optical properties of transition-metal oxides. Radiation Effects, 4 (1), 123-131.

16. Goniakowski, J.; Noguera, C.(2016). Insulating oxide surfaces and nanostructures. Comptes Rendus Physique, 17 (3), 471-480.

17. Stack, D. C.; Curtis, D.; Forsberg, C.(2019). Performance of firebrick resistance-heated energy storage for industrial heat applications and round-trip electricity storage. Applied Energy, 242, 782-796.

18. USDOE (2020). Energy Storage Grand Challenge Roadmap; U.S. Department of Energy, 2020.

19. Cullis, C.; Yates, J.(1964). Reaction of carbon with nitrogen. Transactions of the Faraday Society, 60, 141-148.

20. Patel, P.(2021). White-Hot Blocks as Renewable Energy Storage? Thermal batteries could be the cheap and simple option. IEEE: IEEE Spectrum.

21. Okhay, O.; Tkach, A.(2021). Impact of Graphene or Reduced Graphene Oxide on Performance of Thermoelectric Composites. Journal of Carbon Research, 7 (2), 37.

22. López Prol, J.; Steininger, K. W.; Zilberman, D.(2020). The cannibalization effect of wind and solar in the California wholesale electricity market. Energy Economics, 85, 104552. 
23. Stone, B.; Mallen, E.; Rajput, M.; Gronlund, C. J.; Broadbent, A. M.; Krayenhoff, E. S.; Augenbroe, G.; O’Neill, M. S.; Georgescu, M.(2021). Compound climate and infrastructure events: How electrical grid failure alters heat wave risk. Environmental Science \& Technology, 55 (10), 6957-6964.

24. Laws, N. D.; Anderson, K.; DiOrio, N. A.; Li, X.; McLaren, J.(2018). Impacts of valuing resilience on cost-optimal PV and storage systems for commercial buildings. Renewable Energy, 127, 896-909.

25. Robinson, J. PowerOutage.us. PowerOutage.us (accessed 10/05/2021).

26. Ericson, S. J.; Olis, D. R. (2019). A comparison of fuel choice for backup generators; National Renewable Energy Lab.(NREL), Golden, CO (United States): 2019.

27. NFPA (2021). Standard for Emergency and Standby Power Systems; National Fire Protection Association, 2021.

28. Green, E.(2018). THE USE OF HYDROGEN IN THE IRON AND STEEL INDUSTRY. In U.S. DEPARTMENT OF ENERGY H2@SCALE WORKSHOP, Berry Metal Company.

29. Midrex(2019). 2018 world direct reduction statistics.

30. . Direct Reduced Iron. http://www.iipinetwork.org/wp-content/Ietd/content/direct-reducediron.html (accessed 08/04/2021).

31. Bayon, A.; Bader, R.; Jafarian, M.; Fedunik-Hofman, L.; Sun, Y.; Hinkley, J.; Miller, S.; Lipiński, W.(2018). Techno-economic assessment of solid-gas thermochemical energy storage systems for solar thermal power applications. Energy, 149, 473-484.

32. Post, A.; Rawson, A.; Sugo, H.; Cuskelly, D.; Copus, M.; Bradley, J.; Kisi, E.(2017). Price estimation for miscibility gap alloy thermal storage systems. Renewable Energy and Environmental Sustainability, 2, 32.

33. Smith, J. G.; Naruse, J.; Hiramatsu, H.; Siegel, D. J.(2017). Intrinsic conductivity in magnesium-oxygen battery discharge products: $\mathrm{MgO}$ and $\mathrm{MgO}$. Chemistry of Materials, 29 (7), 31523163.

34. Barsoum, M. W.(2019). Fundamentals of ceramics. CRC press: 2019.

35. Yemata, T. A.; Ye, Q.; Zhou, H.; Kyaw, A. K. K.; Chin, W. S.; Xu, J.(2017). 6 - Conducting polymer-based thermoelectric composites: Principles, processing, and applications. In Hybrid Polymer Composite Materials, Thakur, V. K.; Thakur, M. K.; Pappu, A., Eds. Woodhead Publishing: 2017; pp 169-195.

36. Weber, C. S.; Reis, C. T.; Dada, A.; Masuda, T.; Moscovic, J.(2005). Overview of the underground $34.5 \mathrm{kV}$ HTS power cable program in albany, NY. IEEE Transactions on Applied Superconductivity, 15 (2), 1793-1797.

37. Palmour, J. W.(2014). In Silicon carbide power device development for industrial markets, 2014 IEEE International Electron Devices Meeting, 15-17 Dec. 2014; pp 1.1.1-1.1.8.

38. Datas, A.(2015). Optimum semiconductor bandgaps in single junction and multijunction thermophotovoltaic converters. Solar Energy Materials and Solar Cells, 134, 275-290.

39. Seyf, H. R.; Henry, A.(2016). Thermophotovoltaics: a potential pathway to high efficiency concentrated solar power. Energy \& Environmental Science, 9 (8), 2654-2665.

40. Garcia-Nunez, J. A.; Pelaez-Samaniego, M. R.; Garcia-Perez, M. E.; Fonts, I.; Abrego, J.; Westerhof, R. J. M.; Garcia-Perez, M.(2017). Historical Developments of Pyrolysis Reactors: A Review. Energy \& Fuels, 31 (6), 5751-5775.

41. Miller, J. E.; Ambrosini, A.; Coker, E. N.; Allendorf, M.; McDaniel, A.(2014). Advancing oxide materials for thermochemical production of solar fuels. Energy Procedia, 49, 2019-2026.

42. Munro, R. G.(1997). Evaluated material properties for a sintered alpha-alumina. Journal of the American Ceramic Society, 80 (8), 1919-1928.

43. Mokhena, T. C.; Mochane, M. J.; Sefadi, J. S.; Motloung, S. V.; Andala, D. M.(2018). Thermal conductivity of graphite-based polymer composites. Impact of Thermal Conductivity on Energy Technologies, 181.

44. Schmidt, O.; Melchior, S.; Hawkes, A.; Staffell, I.(2019). Projecting the Future Levelized Cost of Electricity Storage Technologies. Joule, 3 (1), 81-100. 
45. NREL (2020). "2020 Annual Technology Baseline"; Golden, CO: National Renewable Energy Laboratory., 2020. 